\title{
ANÁLISE CRÍTICA DO LIVRO DO ENSINO MÉDIO BRASILEIRO, RELACIONANDO-O COM O LIVRO ACADÊMICO
}

\section{RESUMO}

A elaboração do presente trabalho busca realizar uma análise crítica acerca da maneira como alguns conteúdos de Geografia da População vêm sendo trabalhados no livro didático de Geografia, em específico, conteúdos que trabalham com o acréscimo e o decréscimo do quantitativo populacional como: crescimento demográfico e superpopulação relativa, controle das taxas de mortalidade e natalidade, expectativa de vida, dentre outros aspectos relevantes. Sendo assim, buscamos compreender os fatores que circundam 0 lecionar destes conteúdos, tendo em vista buscar vias de acesso ao melhoramento do ensino, e ainda mostrar que existem falhas, mas também qualidades no modelo de educação atual. Assim, com base nessas questões norteadoras, buscamos contextualizar como os conteúdos referentes aos aspectos populacionais vêm sendo tratados nos livros didáticos de Geografia do ensino médio e suas contribuições para o processo de ensino-aprendizagem.

PALAVRAS-CHAVE: Geografia da População, Ensino/Aprendizagem, Livro Didático.

\section{CRITICAL ANALYSIS OF THE BOOK OF TEACHING MIDDLE BRAZILIAN, RELATING IT TO THE ACADEMIC PAPER}

\section{ABSTRACT}

The preparation of this work search perform a critical analysis about the way some content of geography of the population is being worked in textbook of geography, in specific, content that work with the increase and the decrease of quantitative population as: population growth and overcrowding on, control of mortality and birth rates, life expectancy, among other relevant aspects. Thus, we seek to understand the factors that surround the teach these contents, in order to find paths of access to the improvement of teaching, and also to show that there are flaws, but also qualities in the model of current education. Thus, on the basis of these guiding questions, trying to contextualize how the content relating to populational aspects have been treated in geography textbooks of middle school and their contributions to the teaching-learning process.

KEY-WORDS: Geography of the population, teaching/learning, textbook. 


\section{ANÁLISE CRÍTICA DO LIVRO DO ENSINO MÉDIO BRASILEIRO, RELACIONANDO-O COM O LIVRO ACADÊMICO}

\section{INTRODUÇÃO}

Realizar uma análise acerca dos conteúdos que tratam da população não é tarefa fácil. Isso se deve ao fato de que a população é dinâmica, e sendo assim, buscar delimita-la em seu contexto de crescimento perpassa qualquer ação. Sabemos que os conteúdos que são abordados nos livros didáticos estão muitas vezes carecidos de qualidade, principalmente quando se fala da metodologia usada por muitos autores, a organização estrutural dos conteúdos, a qualidade da linguagem, e o uso adequado de recursos quantitativos, este último, utilizado muitas vezes de forma inadequada em alguns livros didáticos.

É importante destacarmos que o processo de ensino/aprendizagem é composto de etapas subsequentes, por isso relatamos quão importante é que o livro do ensino médio aborde os conteúdos de forma completa, pois somente dessa forma conseguiremos preparar o aluno para acomodar os conteúdos que serão trabalhados no decorrer de sua vida acadêmica, e ainda mais, podermos proporcionar uma melhora na qualidade do ensino.

Sabemos que a elaboração dos livros didáticos é realizada á partir da transposição dos conteúdos produzidos na academia. Contudo, a nossa crítica se volta mais para a maneira como essa transposição está sendo realizada, principalmente no sentido qualitativo, pois um livro didático de ter como funções principais favorecer o crescimento intelecto do aluno, e ainda proporcionar que as arestas do saber sejam preenchidas.

Á partir desses preceitos, relatamos que a crítica realizada neste trabalho não tem aprofundamento intenso, considerando a nossa posição de alunos em processo de formação docente. Desta forma nosso enfoque está voltado mais a análise de conteúdo em si. Esperamos neste sentido contribuir ao menos em parte, para que se possa perceber como podemos realizar uma educação de qualidade, aquela onde há a participação coletiva dos profissionais do ensino, e de toda a sociedade.

\section{A análise dos elementos qualitativos e quantitativos presentes no livro didático do Ensino Médio}

Atualmente, muito se tem debatido acerca da maneira como os conteúdos pertinentes ao livro do ensino médio vêm sendo trabalhados no contexto do ensino brasileiro. Nas últimas décadas, certamente houve grandes avanços neste sentido, mas ainda assim, não podemos deixar de relatar que existem falhas graves que estão atreladas a esse processo de crescimento.

Tratando-se da qualidade do livro do ensino médio, podemos afirmar que existem múltiplas realidades, diversas interações, mas principalmente diferenças que ficam expressas em análises individuais. Os elementos qualitativos que estão presentes nos conteúdos englobam uma gama de fatores que reunidos atendem uma determinada demanda.

Neste sentido podemos afirmar que um conteúdo de qualidade possui atributos e propriedades que o diferencia dos demais não pelo nível de dificuldade, mas pela facilidade com que expressa conteúdos difíceis de serem absorvidos.

Podemos afirmar que um dos pontos mais críticos relacionados ao livro do ensino médio, refere-se á questão do equilíbrio quanto ao uso de elementos qualitativos e quantitativos. Alguns 
livros fazem uso excessivo de elementos de quantificação como gráficos, tabelas, mapas, deixando a qualidade do conteúdo em segundo plano, principalmente alguns livros didáticos de Geografia, que muitas vezes utilizam exageradamente esses elementos quantitativos, deixando a qualidade á margem.

Outra questão a ser levantada diz respeito á ineficiência de alguns conteúdos. Muitos livros encontram-se extremamente resumidos, impossibilitando que o aluno possa assimilar aquilo que está exposto, principalmente nas obras que preservam o lado quantitativo do conteúdo. Por outro lado, alguns conteúdos fazem uso adequado de elementos quantitativos, mas pecam quando não buscam preservar a qualidade da linguagem trabalhada.

É extremamente relevante percebermos a educação como um processo. Assim, entendemos que o conhecimento deve ser adquirido através de etapas ou processos sequenciais, por isso é importante que o livro do ensino médio tenha antes de tudo qualidade, pois ele é a base que possibilitará que o aluno possa acomodar os conteúdos que possivelmente serão trabalhados na sua vivencia acadêmica.

Destacamos que existem pontos positivos e negativos que podem ser encontrados nesses conteúdos. O importante neste momento é procurar despertar um olhar mais crítico diante do que é exposto nos livros quanto aos elementos qualitativos e quantitativos. Esse deve ser o papel daqueles preocupados com a educação no país.

\section{Análise dos conteúdos de Geografia da População no livro do Ensino Médio em relação ao livro Acadêmico.}

O livro do Ensino Médio utilizado nesta pesquisa é o do autor José Willian Vesentini, intitulado Geografia: Geral e do Brasil, enquanto o livro acadêmico é População e Geografia de Amélia Luísa Damiani.

Nosso diagnóstico baseou-se na análise dos conteúdos referentes á Geografia da População que são trabalhados nas obras acima supracitadas. Nossa análise buscou vislumbrar todos os aspectos relevantes, tendo o intuito de mostrar uma pequena faceta da realidade do livro do ensino médio.

A análise dos conteúdos referentes aos livros do ensino médio e acadêmico revelou-nos que estes possuem significativas diferenças, principalmente no que diz respeito ao modo como um assunto de tamanha importância é trabalhado em ambas as obras. Diferenças certamente existem, principalmente no uso da linguagem. Contudo cabe a nós questionarmos até que ponto um conteúdo torna-se insuficiente e/ou ineficiente sendo capaz de comprometer a transmissão do conhecimento.

\section{Crescimento demográfico e superpopulação relativa}

As páginas introdutórias desse conteúdo trazem como tópico de abertura, uma boa apresentação das áreas que possuem um povoamento mais antigo, e também retratam as áreas que foram povoadas mais recentemente.

Vesentini faz uma abordagem bastante clara acerca dos principais elementos que provocam uma distribuição desigual da população no mundo, citando desde os aspectos naturais, até os fatores de ordem social e econômica. Ele mostra de forma bastante objetiva, como tais elementos podem ser influenciadores em uma concentração demográfica maior ou menor em 
determinados lugares. Esse conceito é trabalhado de maneira semelhante á abordagem feita pela autora Amélia Luíza Damiani.

O conteúdo apesar de ser bastante complexo, é pautado em uma linguagem bastante clara, bem trabalhada, atual, de forma a ser assimilado mais facilmente pelos alunos.

\section{Controle de natalidade}

A ideia do controle de natalidade é feita pelo autor á partir dos pontos justificativos e argumentativos, seguindo uma linha descritiva das ideias suscitadas por Malthus, e seguidas pelos Neomalthusianistas (trabalhado no mesmo enfoque de DAMIANI). O livro do ensino médio analisado aborda minuciosamente a questão do desenvolvimento técnico, agindo como fator impactante e de fundamental importância sobre a ótica do controle de natalidade, e do planejamento familiar nos países subdesenvolvidos. Para uma melhor assimilação, Vesentitni cita os problemas tratados no contexto do controle da natalidade (fome, superpovoamento...), relacionando-os com os países onde se observa uma rígida busca sobre o controle desse índice.

\footnotetext{
“Especialmente na China, foram estabelecidas [...] políticas de controle da natalidade extremamente rígidas até mesmo autoritárias, pois os governos tiraram a liberdade dos casais de construírem uma família grande ou da mulher dispor livremente seu corpo." (VESENTINI, 2005, P.261).
}

O tratamento teórico realizado pelo autor é feito de uma forma bastante contundente, apresentado em aspectos bastante detalhados, ressaltando os principais elementos dessa dinâmica, possuindo uma linguagem mais intensa referente ao nível de ensino médio.

\section{Crescimento demográfico}

De acordo com Vesentini (2005), o vetor do crescimento demográfico é debatido de maneira processual, analítica, ressaltando quais as causas e consequências "deste," e mostrando sua forma em países com alto/baixo crescimento demográfico. Explica detalhadamente a intensificação do ritmo de crescimento demográfico, explica a importância dos movimentos migratórios internacionais como fatores de recuo e crescimento populacional, bem como as diferenças entre nascimentos e morte se apresentando como fatores de diferenciação demográfica. O livro mostra de forma muito simples, como a taxa natural de crescimento da população se modifica nos diferentes períodos históricos da sociedade.

Vesentini faz o uso constante de cartas, gráficos e fotos, de forma que o aluno possa interagir dentro do contexto, e sendo assim, uma maneira do aluno assimilar e compreender mais facilmente a temática abordada.

\section{Taxas de mortalidade}

O autor segue uma excelente linha de abordagem dentro do contexto da mortalidade, realiza uma divisão do assunto em tópicos que se dividem em subtópicos, fazendo com que dessa forma, o assunto não se torne acumulativo nem tão pouco disperso. Os subtópicos fazem uma releitura e um aprofundamento dos tópicos iniciais, sem deixar dúvidas quanto aos conceitos. $\mathrm{O}$ 
texto analisado aborda inicialmente os índices de mortalidade nos países desenvolvidos e subdesenvolvidos, mostra os elementos que interferem e atuam nessa dinâmica, e como cada país se coloca diante dessa questão de desenvolvimento populacional.

Assim como descrito por DAMIANI (2001) em População e Geografia, a discussão sobre os índices de mortalidade feita pelo autor é semelhante à mesma, no sentido em que ele aborda de forma direta fatores como a educação, padrão de vida, saneamento, e principalmente os progressos da medicina como sendo propiciadores desse recuo.

O autor ainda faz uma leitura complementar sobre a AIDS e suas consequências sobre o aumento ainda maior dos índices de mortalidade. Essa abordagem por ser atual, faz com que o aluno reflita sobre esse problema demográfico, que fragiliza muitas populações - em especial o continente Africano.

\section{Índices de natalidade}

O declínio das taxas de nascimento é citado no texto de forma bastante prolongada e detalhada. São recolocados em questão os fatores econômicos, religiosos, culturais..., ressaltando claramente, os índices mais altos sendo encontrados nos países Africanos. O autor trabalha a questão da urbanização e da busca por uma melhor renda como fatores de muita significância dentro dessa abordagem. No geral o tema é abordado de maneira fragmentada, podendo ser compreendido em partes, indo em seguida para uma lógica de totalidade, facilitando uma melhor compreensão.

\section{Expectativa de vida}

A abordagem feita por Vesentini (2005) no que diz respeito á expectativa de vida, é realizada de maneira muito curta. $O$ autor não põe em questão todos os elementos que influenciam o indicador de qualidade de vida. Os elementos que são expostos são tratados de forma muito reduzida, e outros não são nem contextualizados. Com base no trabalho da autora Amélia Damiani que é abordado detalhadamente, a temática do livro de Vesentini sobre expectativa de vida, não é apresentada claramente, o que pode mascarar algumas informações de cunho relevante ao aprendizado. Nesse tópico, o autor trabalha mais sobre uma lógica quantitativa, que de certa forma não menospreza o conteúdo, mas deveria haver um balanceamento entre esta e a qualitatividade.

\section{População ativa e população inativa}

Os conceitos de população economicamente ativa e inativa são trabalhados pelo autor de forma clara nos pontos abordados, porém sem muito aprofundamento. Ele coloca tabelas para servirem como auxílio na compreensão, utiliza mapas temáticos sobre população desempregada, o que facilita de certa forma o entendimento. É feito uma divisão dos setores de atividade econômica, sendo também contextualizada a relação entre a dinâmica populacional e as possibilidades de empregabilidade.

"[...] os países que possuem menores taxas de natalidade e de mortalidade, e, portanto, menor porcentagem de crianças, são os que têm maior proporção de população ativa." (VESENTINI, 2005. P.289). 
A questão da renda é tratada de forma bem superficial, porém compreensiva, mostrando mais a divisão desigual da renda no mundo, diferentemente de População e Geografia, onde é feito toda uma contextualização acerca do processo de trabalho, do acúmulo de lucro, e consequentemente das formas de apropriação do salário pelo homem.

As temáticas anteriormente trabalhadas são aprofundadas em alguns pontos, e superficiais em outros, mas no geral a linguagem trabalhada bastante proveitosa e de fácil entendimento ao aluno do ensino médio. As imagens são bem atuais e os exemplos consideravelmente dinâmicos, de maneira a ser um contexto muito proveitoso.

\section{REFERÊNCIAS BIBLIOGRÁFICAS}

1. DAMIANNI, Amélia Luíza. População e Geografia. 5. ed. Volume único. São Paulo: Contexto, 2001.

2. VESENTINI, José Willian. Geografia: Geral e do Brasil. Volume único. São Paulo: ática, 2005. 